\title{
فعالية تطبيق الطريقة المباشرة في رفع كفاءة المحادثة لدى تلاميذ المدرسة العالية التابعة لمعهد السلطان حسن الدين في ولاية غووا
}

\author{
Azizul Hakim ${ }^{1}$, Sri Adhayani ${ }^{2}$ \\ 1, 2Universitas Islam Negeri Alauddin Makassar
}

1,2Jl. H. M. Yasin Limpo No. 36 Romang Polong, Kec. Somba Opu, Kab. Gowa, Sulawesi Selatan Email: azizabumuflih@uin-alauddin.ac.id' ${ }^{1}$, sriadhayani159@gmail.com²

Nomor Kontak Penulis Pertama: 081343637009

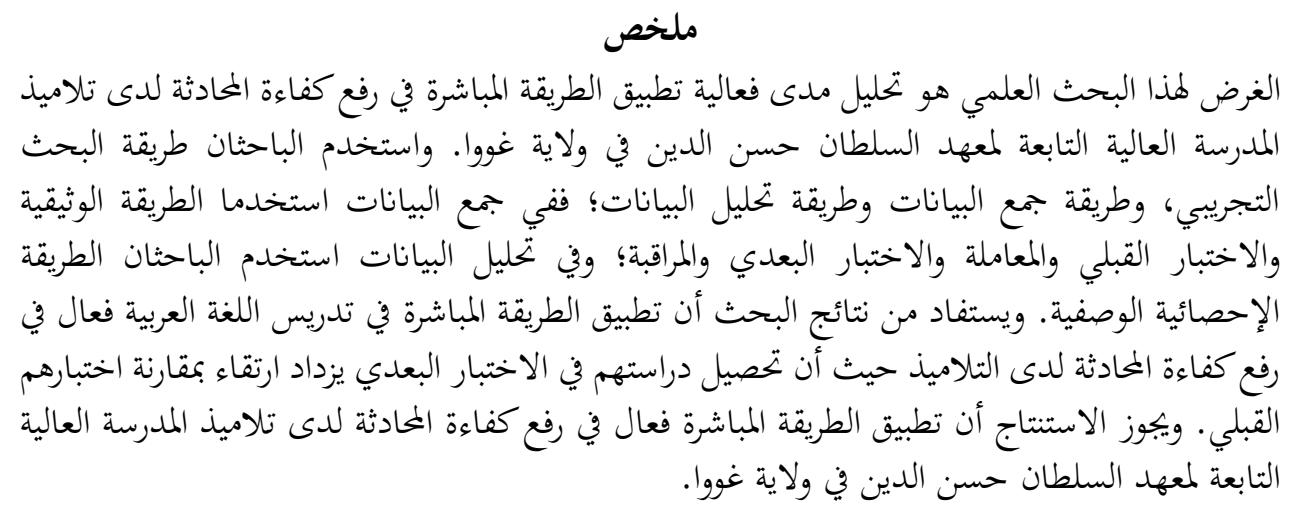

\section{Abstrak:}

Tujuan penelitian ilmiah ini adalah menganalisis efektivitas penerapan metode langsung dalam meningkatkan kemampuan bercakap siswa Madrasah Aliyah Pondok Pesantren Sultan Hasanuddin Kabupaten Gowa. Peneliti menggunakan metode penelitian eksperimen, metode pengumpulan data dan metode analisis data. Dalam mengumpulkan data, peneliti menggunakan metode dokumentasi, tes awal, perlakuan, tes akhir, dan observasi. Dalam menganalisis data, peneliti menggunakan metode statistik deskriptif. Dari hasil penelitian diperoleh bahwa penerapan metode langsung dalam mengajarkan bahasa Arab, efektif dalam meningkatkan kemampuan bercakap siswa di mana hasil belajar mereka pada tes akhir meningkat dibandingkan dengan tes awal. Dari hasil tersebut dapat disimpulkan bahwa penerapan metode langsung, efektif dalam meningkatkan kemampuan bercakap siswa Madrasah Aliyah Pondok Pesantren Sultan Hasanuddin Kabupaten Gowa.

$$
\begin{aligned}
& \text { كلمات مفتاحية } \\
& \text { الطريقة المباشرة، كفاءة المحادثة، فعالية تطبيق الطريقة }
\end{aligned}
$$

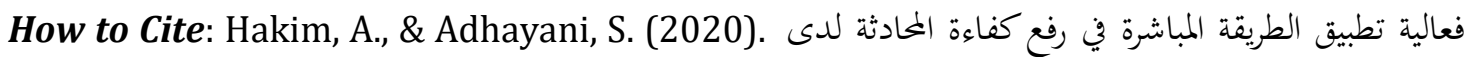
.تلاميذ المدرسة العالية التابعة لمعهد السلطان حسن الدين في ولاية غووا Tarbiyah dan Keguruan, 23(2), 374-386. https://doi.org/10.24252/lp.2020v23n2i15. 
اهتمت المجتمعات الإسلامية غير العربية بتعليم اللغة العربية إيمانا منها بأن اللغة العربية من أهم

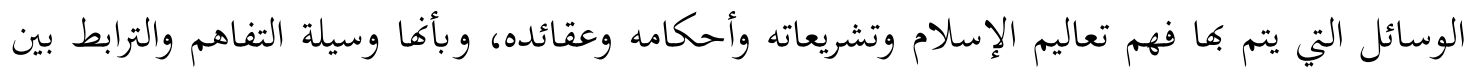

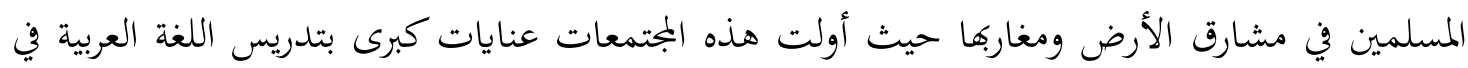

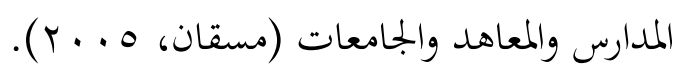
تعلم اللغة العربية كلغة أجنبية يخالف تعلم لغة الأم فلا بد أن يختلف منهج تعليمها إما في الطريقة أو في المواد أو في عملية تعليمها. من العوامل التي لا تثير رغبة التلاميذ وحماستهم في تعلم اللغة العربية هي قلة تقدم وتطور الطريقة ومنهج تعليم اللغة العربية بذاته. وبالنظر إلى سرعة تطور علم اللغة فنحس تأخر طريقة ومنهج تعليم اللغة العربية (Chotib, 1976). فالطريقة التعليمية هي من إحدى العناصر المهمة للحصول على الأهداف التعليمية والتعلمية (Sahrani, 2019). لقد مهد مؤلفو كتب دروس اللغة العربية الإندونيسيون طريقة تعليم اللغة العربية للإندونيسيين

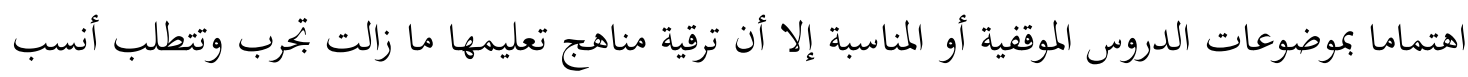
طريقة. ومن الطرائق المجربة والمتطورة هي الطريقة المباشرة.

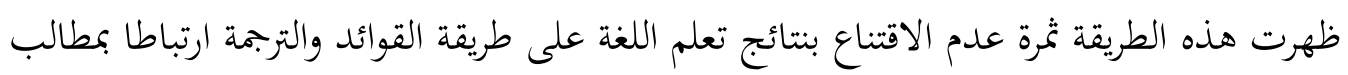

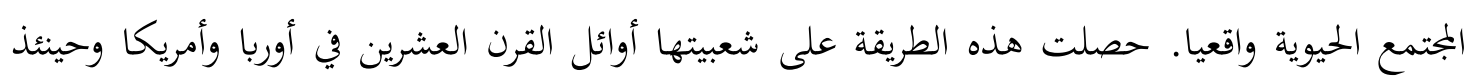
استخدمت هذه الطريقة لتعليم اللغة العربية سواء أكان في بلاد العرب أو البلاد الإسلامية في آسيا بل في إندونيسيا (Efendi, 2005).

وفيما يتعلق ببعض التحديات في تعليم وتعلم اللغة العربية كلغة أجنبية أو لغة ثانية، فإن إحدى الاستراتيجيات الرئيسية التي يمكن تطبيقها هي إنشاء بيئة تعليمية داعمة يمكن أن تسهل عملية تعلم اللغة لتصبح أكثر جاذبية وتحسينًا (Nasution, 2020). وتطبيق الطريقة المباشرة من إحدى المحاولات فئية في إنشاء البيئة التعليمية الجيدة. وذلك ما يلهم الباحثين للقيام بالبحث التجريبي عن فعالية تطبيق الطريقة المباشرة في رفع كفاءة المحادثة لدى تلاميذ المدرسة العالية التابعة لمعهد السلطان حسن الدين فيحن في ولاية غووا. الدراسة السابقة في البحث عن المراجع المتصلة بالمشكلات الرئيسية التي أراد أن يبحث منها الباحثان، فقاما

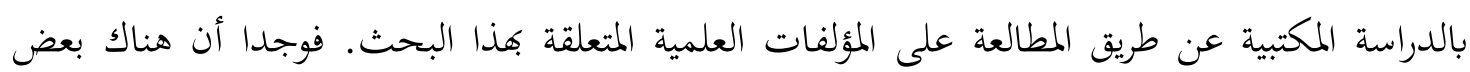
الرسائل العلمية التي لها علاقة بما يبحثانه منها: 
قدم سمود دكير في رسالته العلمية بموضوع "تطبيق الطريقة المباشرة في تعليم اللغة العربية (بحث وصفي في مدرسة سلم الهدى المتوسطة فونوروكو)" نتائج البحث وهي (1) إن خطوات تطبيق الطريقة

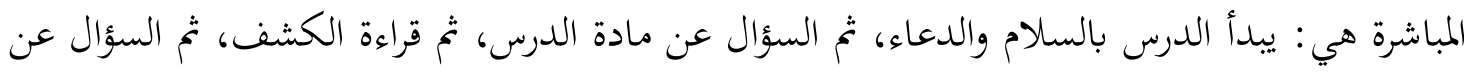
الدرس الماضي، ثم عرض المفردات الجلديدة وتكريرها ثم السؤال عن معنى كل منها، ثم القيام بالتعليم مستعينا

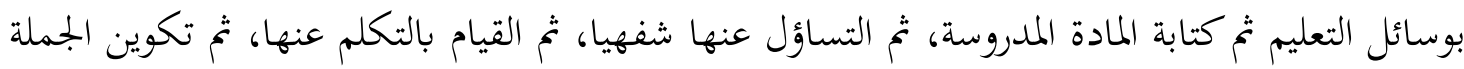

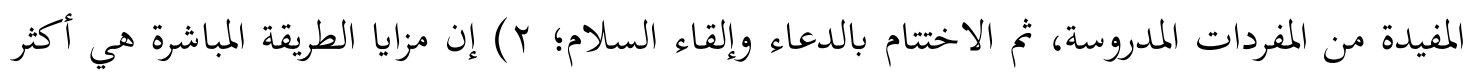
التلاميذ لهم الكفاءة الجيدة في مهارة الكلام، واستولى أكثرهم التلفظ الجيد في كلامهم اليومي، ولا يخافون من الأخطاء في الكلام، ويتحمسون أثناء التدريس، ويعرفون كثيرا من المفردات؛ وإن عيوب الطريقة هي ليس جميع المدرسين لهم كفاءة اللغة العربية جيدا، وصعوبة تطبيقها لمن لم يستولي الهجائي جيدة، والمنع باستخدام لغة الأم يؤدي إلى أخطاء الإدراك لبعض التلاميذ، وتحتاج الأوقات أكثر لشرح الكلمة وفهم المادة وإعداد وسائل التعليم، وبتعل بعض التلاميذ يملّون سريعا أثناء التدريس، وعدد الوساء التوسائل التعليمية الناقص للمدرسة (دكير، 1 ا • ץ).

وحصل زين الرازقين في رسالته العلمية بموضوع "فعالية استخدام الطريقة المباشرة في تعليم مهارة

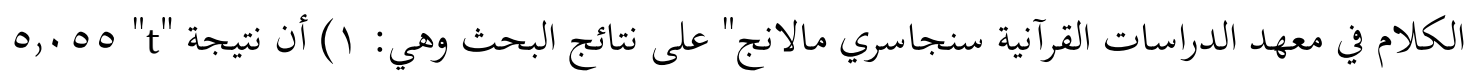

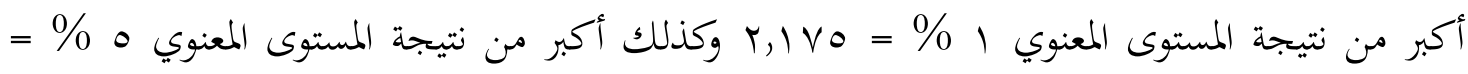
ـ ץ . , . . وذلك بمعنى أن فروض هذا البحث مقبول؛ ب) أن استخدام الطريقة المباشرة لترقية مهارة الكلام يجعل التلاميذ يشعرون بالحماسة في عملية التعليم وفي سهولة التعبير الشفهي. وذلك بمعنى أن استخدام

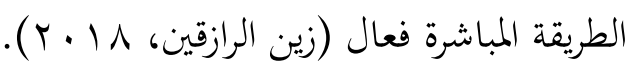
وقدم محمد ثابرين في بحثه العلمي بعنوان "تطبيق الطريقة المباشرة في تعليم الحوار (دراسة بتحيبية بـ (MAN 2 Sigli) نتائج البحث التي تدل على أن الفروض مقبولة لأن النتيجة من ت الاختبار (T-Test)

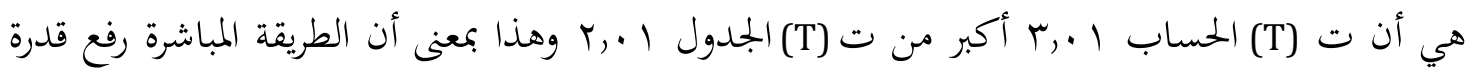

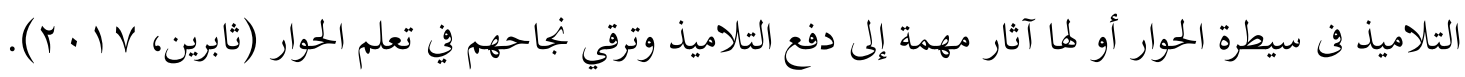

\section{أغراض البحث}

الأغراض التي يراد الحصول عليها في هذا البحث هي معرفة كفاءة المحادثة لدى التلاميذ قبل تطبيق الطريقة المباشرة ومعرفة كفاءة المحادثة لدى التلاميذ بعد تطبيق الطريقة المباشرة ومعرفة فعالية تطبيق الطريقة المباشرة في رفع كفاءة المحادثة لدى تلاميذ المدرسة العالية التابعة لمعهد السلطان حسن الدين في ولاية غووا. 


\section{منهج البحث \\ نوع البحث}

هذا البحث كمي النوع لما أنه يستخدم البيانات المرقمة المحللة تحليلا إحصائيا. ويُستخدم هذا

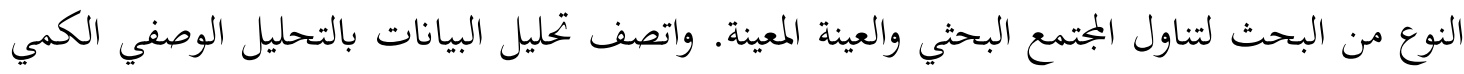

الذي يراد منه اختبار الفروض التي تم تعيينها (Sugiono, 2011).

مجتمع البحث وعينته

مجتمع البحث هو جميع موضوعات البحث التي تتكون من إنسان وحيوان ونبات وظاهرة درجة

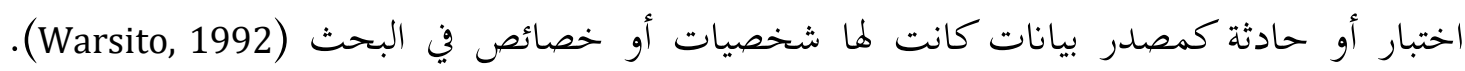

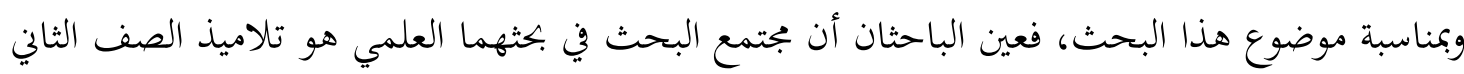

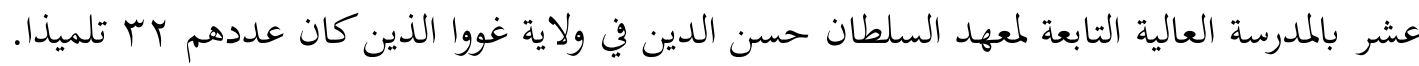

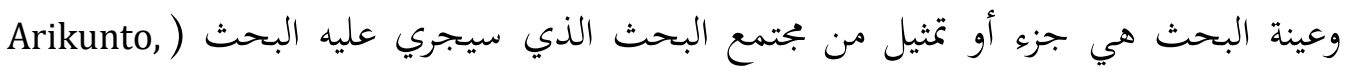

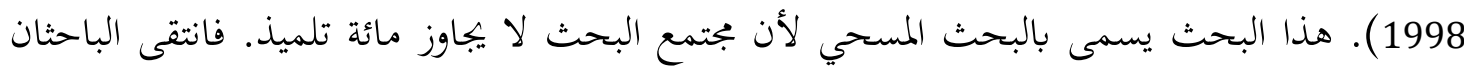

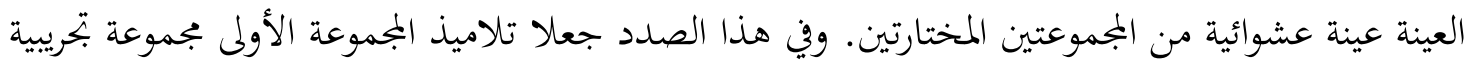
وتلاميذ المجموعة الثانية مجموعة مراقبة. طريقة جمع البيانات للحصول على البيانات الصحيحة الدقيقة من البحث انتهج الباحثان خطوات وهي (1) الاستعداد؛

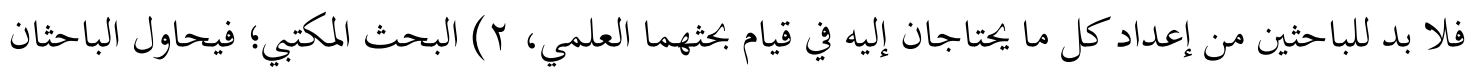

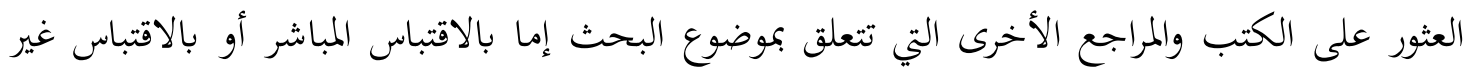

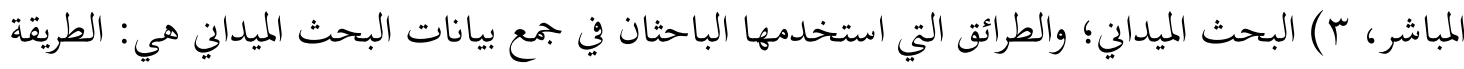
الوثيقية والاختبار القبلي والمعاملة والاختبار البعدي والمراقبة.

أووات البحث

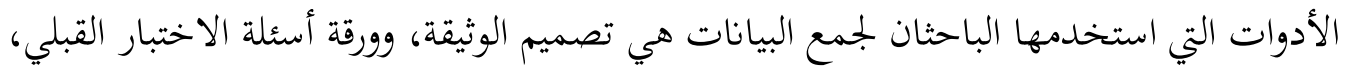
والمعاملة (تطبيق الطريقة المباشرة)، وورقة أسئلة الاختبار البعدي، وطريقة الئان المراقبة. طريقة تحليل البيانات

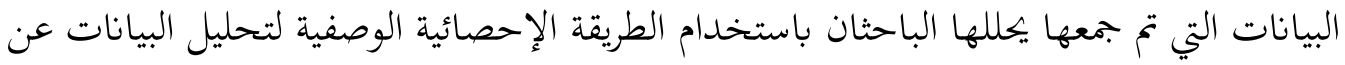

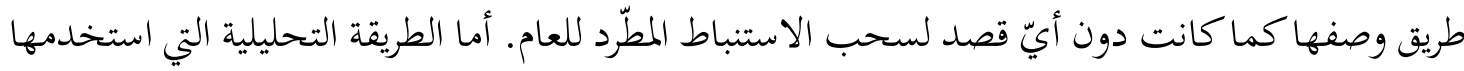


الباحثان في تنظيم البيانات حتى تكون تركيب نظام البحوث فهي التحليل الإحصائي الوصفي وطريقة

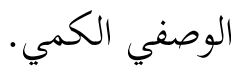

نتائج البحث

\section{فعالية تطبيق الطريقة المباشسة في رفع كفاءة المحادثة لدى التلاميذ}

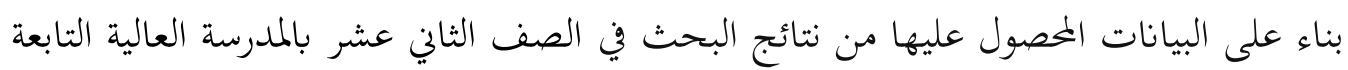

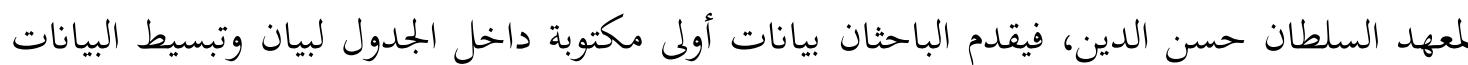

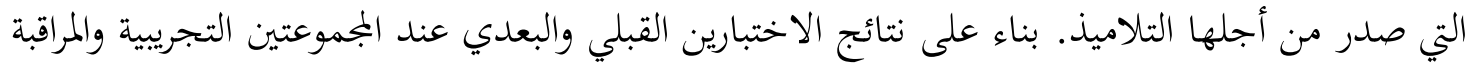

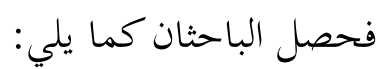

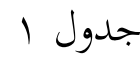

نتائج الاختبارين القبلي والبعدي عند المجموعتين التجريبية والمراقبة

\begin{tabular}{|c|c|c|c|c|c|}
\hline \multicolumn{2}{|c|}{ المجموعة المراقبة } & \multicolumn{2}{|c|}{ المجموعة التجريبية } & \multirow{2}{*}{ المستجيبون } & \multirow{2}{*}{ 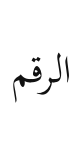 } \\
\hline البعدي & القبلي & البعدي & القبلي & & \\
\hline 10 & Nr & 91 & 10 & المستجيب الأول & .1 \\
\hline $7 \varepsilon$ & $0 \wedge$ & 19 & 79 & المستجيب الثاني &.$t$ \\
\hline$\wedge \varepsilon$ & $\wedge$. & $9 \varepsilon$ & Vo & المستجيب الثالث &.$r$ \\
\hline$\Lambda \varepsilon$ & 11 & 97 & $\Lambda \varepsilon$ & المستجيب الرابع & $\varepsilon$ \\
\hline VT & 79 & 9. & v. & المستجيب الخامس & .0 \\
\hline ᄉ. & VY & $q r$ & $v r$ & المستجيب السادس & .7 \\
\hline 70 & 09 & ᄉ. & 09 & المستجيب السابع &. $\mathrm{V}$ \\
\hline 70 & Tr & $\wedge \varepsilon$ & 7. & المستجيب الثامن & .1 \\
\hline$\vee \wedge$ & Vr & 10 & 09 & المستجيب التاسع & .9 \\
\hline$v \cdot$ & $7 \mathrm{~V}$ & 9. & 77 & المستجيب العاشر & .1 . \\
\hline or & 00 & 91 & $V \varepsilon$ & المستجيب الحادي عشر & .11 \\
\hline$v \cdot$ & 79 & $\wedge$. & or & المستجيب الثاني عشر & $.1 \%$ \\
\hline ro & Tr & vo & 01 & المستجيب الثالث عشر & $.1 \%$ \\
\hline NT & $\vee \wedge$ & 97 & $\wedge$. & الممستجيب الرابع عشر & $.1 \leqslant$ \\
\hline
\end{tabular}




\begin{tabular}{|c|c|c|c|c|c|}
\hline 0 . & $\varepsilon r$ & vo & 0 . & المستجيب الخامس عشر & .10 \\
\hline 77 & 7. & VT & $\varepsilon r$ & المستجيب السادس عشر & .17 \\
\hline $\begin{array}{l}=\sum X_{2} \\
11 \cdot V\end{array}$ & $\begin{array}{l}=\sum X_{1} \\
1 \cdot \sum 0\end{array}$ & $\begin{array}{l}=\sum X_{2} \\
\mid \text { |人V }\end{array}$ & $\begin{array}{l}=\sum X_{1} \\
1.0 .\end{array}$ & \multicolumn{2}{|c|}{ مجموع النتائج } \\
\hline
\end{tabular}

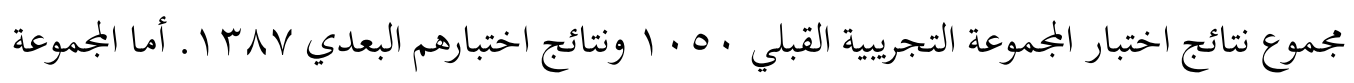
المراقبة فحصلوا على 0ـ • 1 عند الاختبار القبلي و • • 11 عند الاختبار البعدي.

جدول

النسبة المائوية

نتائج اختباري المجموعة التجريبية القبلي والبعدي

\begin{tabular}{|c|c|c|c|c|c|c|}
\hline \multicolumn{2}{|c|}{ الاختبار البعدي } & \multicolumn{2}{|c|}{ الاختبار القبلي } & \multirow{2}{*}{ فاصلة } & \multirow{2}{*}{ المستويات } & \multirow{2}{*}{ الرقم } \\
\hline$\%$ & $\mathrm{~F}$ & $\%$ & $\mathrm{~F}$ & & & \\
\hline$\% \circ \neg, \curlyvee \circ$ & 9 & - & - & $1 \ldots-\wedge 7$ & متاز & .1 \\
\hline$\% \leq r, \vee \circ$ & V & $\% r \vee, 0$ & 7 & $\Lambda_{0}-v_{1}$ & جيد جدا &.$T$ \\
\hline- & - & $\% \Gamma \vee, 0$ & 7 & $v \cdot-07$ & جيد & r \\
\hline- & - & $\%$ ro & $\varepsilon$ & $00-\leqslant 1$ & مقبول & $\varepsilon$ \\
\hline- & - & - & - & $\varepsilon \cdot-r\rceil$ & راسب & 0 \\
\hline$\% 1 \ldots$ & 17 & $\% 1 \ldots$ & 17 & & & و \\
\hline
\end{tabular}

بناء على البيانات السابقة رأينا أن نتائج مائوية الاختبار القبلي لدى تلاميذ المجموعة التجريبية

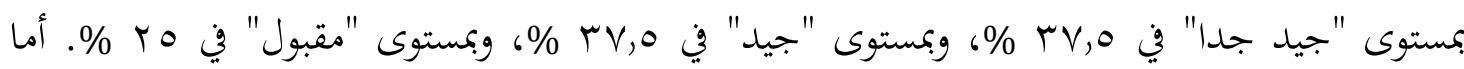

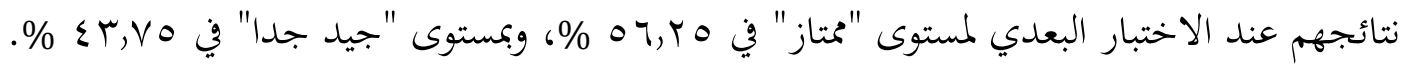
جدول r النسبة المائوية نتائج اختباري المجموعة المراقبة القبلي والبعدي

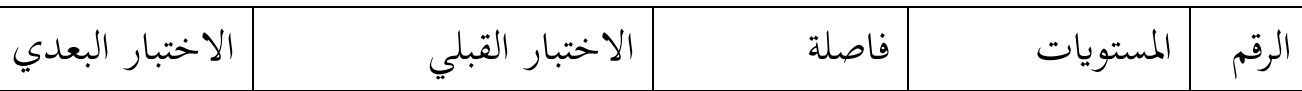




\begin{tabular}{|c|c|c|c|c|c|c|}
\hline$\%$ & $\mathrm{~F}$ & $\%$ & $\mathrm{~F}$ & & & \\
\hline - & - & - & - & $1 \ldots-17$ & متمتاز & .1 \\
\hline$\% \varepsilon r, \vee \circ$ & V & $\% r \vee, o$ & 7 & $1_{0}-v_{1}$ & جيد جدا &.$r$ \\
\hline$\% \varepsilon r, \vee \circ$ & v & $\% \varepsilon r, \vee \circ$ & v & $v \cdot-0$. & جيد & r \\
\hline$\%$ ૫, Ү० & 1 & $\% \backslash$ Y, 0 & r & $00-\leqslant 1$ & مقبول &.$\varepsilon$ \\
\hline$\%$ ૫, Ү० & 1 & $\%$ ૫, Ү० & 1 & $\varepsilon \cdot-r_{\tau}$ & راسب & .0 \\
\hline$\% 1 \ldots$ & 17 & $\% 1 \ldots$ & 17 & & & $\Rightarrow$ \\
\hline
\end{tabular}

بناء على البيانات السابقة رأينا أن نتائج مائوية الاختبار القبلي لدى تلاميذ المجموعة المراقبة بمستوى

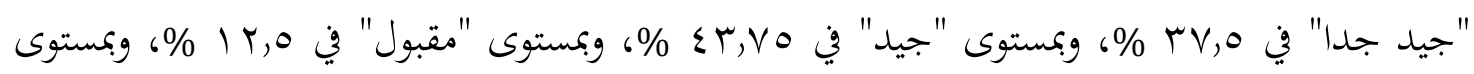

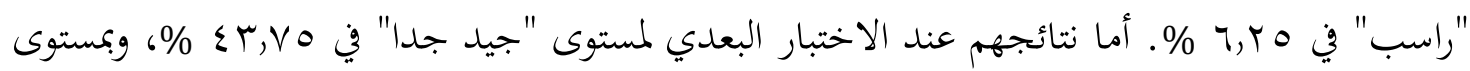

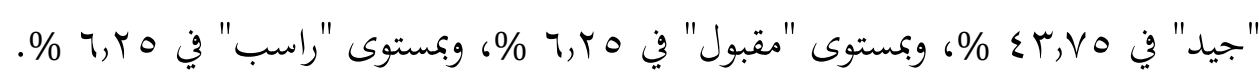
وبمناسبة نتائج هذا البحث نرى أن تطبيق الطريقة المباشرة عامل من عوامل مؤيدة في رفع نتائج دراسة التلاميذ. إضافة إلى تأثير نتائج التلاميذ لقد أثرت كذلك في أنشطتهم. وهذه كما تتمثل في العملية

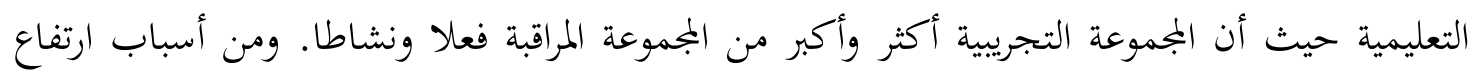
حماسة التلاميذ في اشتراك الدراسة لا يخلو من خصائص وتفوقات الطريقة المباشرة على غيرها من الطرق التعليمية حيث أن الدراسة تقدم باللغة المراد تدريسها مباشرة دون أي وساطة حتى يمكن التلاميذ من فهم

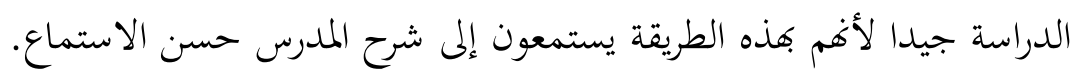

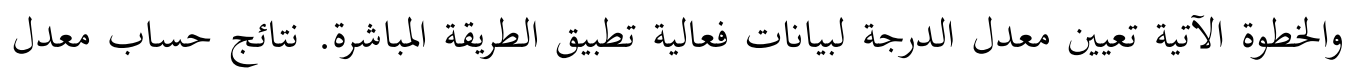
درجات التلاميذ ومستوى انخرافها من نتائج الاختبارين القبلي والبعدي باستخدام الرموز التالية: أ. أمعدل درجات المجموعة التجريبية

$$
\begin{aligned}
& X_{1}=\frac{\sum X_{1}}{N} \\
& X_{1}=\frac{1050}{16} \\
& X_{1}=65.62
\end{aligned}
$$




$$
\begin{aligned}
& X_{2}=\frac{\sum X_{2}}{N} \\
& X_{2}=\frac{1387}{16} \\
& X_{2}=86.68
\end{aligned}
$$

$$
\text { ب اختبار البعدي }
$$

ب. معدل درجات المجموعة المراقبة

ا ـ الاختبار القبلي

$$
\begin{aligned}
& X_{1}=\frac{\sum X_{1}}{N} \\
& X_{1}=\frac{1045}{16} \\
& X_{1}=65.31
\end{aligned}
$$

$$
\begin{aligned}
& X_{2}=\frac{\sum X_{2}}{N} \\
& X_{2}=\frac{1107}{16} \\
& X_{2}=69.18
\end{aligned}
$$

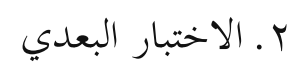

بناء على معدل الدرجات فنرى أن نتائج الاختبار القبلي لدى تلاميذ المجموعة التجريبية هي

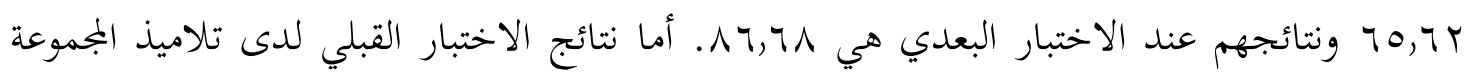
المراقبة هي 10,10 ونتائجهم عند الاختبار النهائي هي 1 |,79 ـ وبمناسبة التنويع الوصفي لنتائج اختبار التلاميذ، فنوافق جدول تقييم مرجع القياس (PAP) كما يلي: 
جدول

جدول تقييم مرجع القياس (PAP)

\begin{tabular}{|c|c|c|}
\hline درجة فهم المواد & مستويات & الرقم \\
\hline $1 \ldots-\wedge 7$ & متمتاز & .1 \\
\hline $1_{0}-v_{1}$ & جيد جدا &.$r$ \\
\hline$v \cdot-0 y$ & جيد & r \\
\hline $00-\varepsilon 1$ & مقبول &.$\varepsilon$ \\
\hline$\varepsilon \cdot-r \tau$ & راسب & .0 \\
\hline
\end{tabular}

بناء على جدول تقييم المرجع المستخدم في المدرسة العالية التابعة لمعهد السلطان حسن الدين،

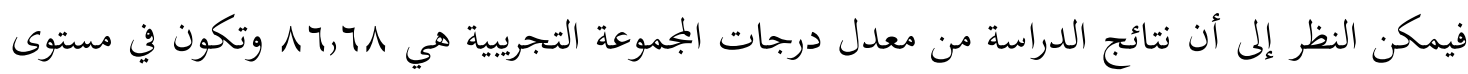
"متاز" . أما نتائج الدراسة من معدل درجات المجموعة المراقبة هي 19,19 19 وتكون في مستوى "جيد". فالخطوة الآتية هي تعيين مستوى القيم ويليه تعيين مستوى الانحراف باستخدام الرموز كما يلي:

$$
\begin{aligned}
& \text { ا. مستوى القيم } \\
& S S_{1}=\sum X_{1}{ }^{2}-\frac{\left(\sum X_{1}\right)^{2}}{N_{1}} \\
& S S_{2}=\sum X_{2}{ }^{2}-\frac{\left(\sum X_{2}\right)^{2}}{N} \\
& =71364-\frac{(1050)^{2}}{16} \\
& =121253-\frac{(1387)^{2}}{16} \\
& =71364-\frac{1102500}{16} \\
& =121253-\frac{1923769}{16} \\
& =71364-68906,25 \\
& =121253-120235,56 \\
& =2457,75 \\
& =1017,44 \\
& S S_{1}=\sum X_{1}{ }^{2}-\frac{\left(\sum X_{1}\right)^{2}}{N_{1}} \\
& S S_{2}=\sum X_{2}{ }^{2}-\frac{\left(\sum X_{2}\right)^{2}}{N} \\
& =71197-\frac{(1045)^{2}}{16} \\
& =79405-\frac{(1107)^{2}}{16}
\end{aligned}
$$




$$
\begin{aligned}
& =71197-\frac{1092025}{16} \\
& =71197-68251,56 \\
& =3743,44
\end{aligned}
$$

$$
\begin{aligned}
& S D_{1}=\sqrt{\frac{S S_{1}}{N-1}} \\
& =\sqrt{\frac{2457,75}{16-1}} \\
& =\sqrt{\frac{2457,75}{15}} \\
& =\sqrt{163,85} \\
& =12,80 \\
& S D_{1}=\sqrt{\frac{S S_{1}}{N-1}} \\
& =\sqrt{\frac{3743,44}{16-1}} \\
& =\sqrt{\frac{3743,44}{15}} \\
& =\sqrt{249,56} \\
& =15,797 \\
& S D_{2}=\sqrt{\frac{S S_{2}}{N-1}} \\
& =\sqrt{\frac{2814,44}{16-1}} \\
& =\sqrt{\frac{2814,44}{15}} \\
& =\sqrt{187,62} \\
& =13,697 \\
& \text { و وقي بحربة الفروض يقام بها استخدام "uji t بالرموز كما يلي: } \\
& =\quad \frac{86.68-69.18}{\sqrt{\frac{1017.44+2814.44}{16+16-2}\left(\frac{1}{16}+\frac{1}{16}\right)}} \\
& =\quad \frac{17.5}{\sqrt{\frac{3831.88}{30}\left(\frac{2}{16}\right)}}
\end{aligned}
$$




$$
\begin{aligned}
& =\frac{17.5}{\sqrt{(127.72)(0.125)}} \\
& =\frac{17.5}{\sqrt{15.96}} \\
& =\frac{17.5}{3.99} \\
& =4,38
\end{aligned}
$$

نتائج بتربة الفروض التي قيم بها استخدام "uji قيمة tabel $t_{\text {end }}$ tabel و Ho مردودة. ونستنتج أن تطبيق الطريقة المباشرة فعال في رفع مستوى كفاءة المحادثة لدى تلاميذ المدرسة العالية التابعة لمعهد السلطان حسن الدين في ولاية غووا.

\section{الحخلاصة والمقتزحات}

بعد أن سرد الباحثان عن فعالية تطبيق الطريقة المباشرة في رفع كفاءة المحادثة لدى تلاميذ المدرسة العالية التابعة لمعهد السلطان حسن الدين في ولاية غووا فيمكن أن تسحب الخلاصات أن: (1) كفاءة

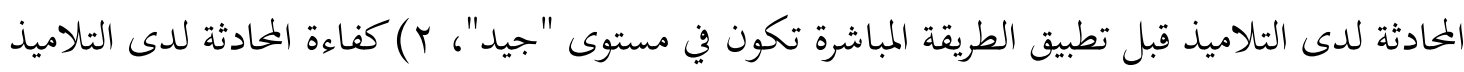
بعد تطبيق الطريقة المباشرة تكون في مستوى "متاز"، ب) تطبيق الطريقة المباشرة فعال في رفع كفاءة المحادثة لدى تلاميذ المدرسة العالية التابعة لمعهد السلطان حسن الدين في ولاية غووا. بناء على نتائج البحث، فتقدم بعض المقترحات هي: (1) يرجى من مدرسي اللغة العربية بالمدرسة العالية التابعة لمعهد السلطان حسن الدين أن يرقوا تطبيق الطريقة المباشرة ولا ينتهجوا بمثل تطبيق هذه بـاء الطريقة فحسب بل يوافقونه مع الأحوال الدراسية، ب) ينبغي للمدرسين أن يجفظوا ويرفعوا مستوى نتائج

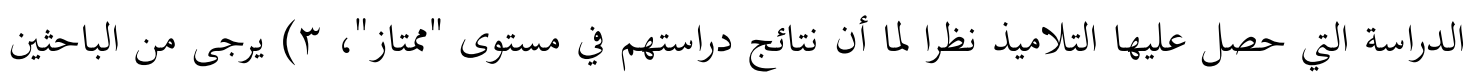
أن يقووا نتائج هذا البحث قياما بالبحث عن فعالية الطرق الأخرى التي تؤثر كذلك في رفع نتائج دراسة اللغة العربية لدى التلاميذ.

\section{المراجع العربية}

$$
\text { إبراهيم، ع. (7 9 } 1 \text { (). الموجه الفني لملدرسي اللغة العربية. مصر: دار المعارف. }
$$

أحمد، م.ع. (9 9 ( ). طرق تعليم اللغة العربية. القاهرة: مكتبة النهضة المصرية. 


$$
\begin{aligned}
& \text { أرشد، أ. (9191 (1). مدخل إلى طرق تعليم اللغة الأجنبية لملدرسي اللغة العببية. أوجونج فاندانج: الأحكام. } \\
& \text { إسماعيل، ز. (1991 ).. طرق تلديس اللغة العربية. إسكندرية: دار المعرفة والجامعية. } \\
& \text { ثابرين، م. (V V • †). تطبيق الطريقة المباشرة في تعليم الحوار بـ MAN } 2 \text { SIGLI. لساننا: مجلة دورية علمية }
\end{aligned}
$$

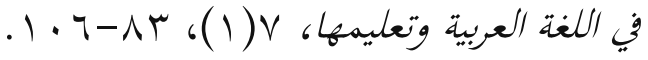

$$
\begin{aligned}
& \text { دكير، س. (1 | • (Y). تطبيق الطريقة المباشرة في تعليم اللغة العربية (بحث وصفي في مدرسة سلم الهدى } \\
& \text { التوسطة فونوروكو). رسالة. مالانج: جامعة مولانا مالك إبراهيم الإسلامية الحكومية. } \\
& \text { زين الرازقين. (1 ا • ب). فعالية استخدام الطريقة المباشرة في تعليم مهارة الكلام في معهد الدراسات القرآنية } \\
& \text { سنجاساري مالانج. رسالة. مالانج: جامعة مولانا مالك إبراهيم الإسلامية الحكومية. } \\
& \text { الزاوي، ط. أ. (د.س.). ترتيب القاموس المحيط على طريقة المصباح المنير وأساس البلاغة. بيروت: دار } \\
& \text { الفكر. } \\
& \text { مجمع اللغة العربية. (د.س.). المعجم الوسيط. طهران: المكتبة العلمية. } \\
& \text { مسقان، د. (0 . . ץ). نحو استراتيجية تعليم اللغة العربية الفعالة "قراءة في المنهج والطريقة من خلال تجربة }
\end{aligned}
$$

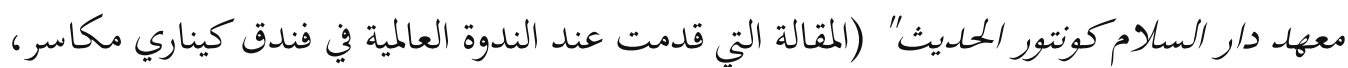

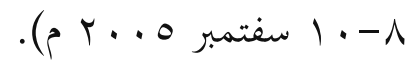

$$
\begin{aligned}
& \text { عند البرنامج التدريبي في المملكة العربية السعودية ع ع ا هـ). } \\
& \text { معروف، ن. م. (19191). خصائص العربية وطرائق تلديسها. بيروت: دار النفائس. } \\
& \text { المراجع غير العربية }
\end{aligned}
$$

Arikunto, S. (1998). Prosedur Penelitian. Jakarta: Bumi Aksara.

Chotib, A. (1976). Pedoman Pengajaran Bahasa Arab. Jakarta: Departemen Agama RI.

Efendi, A. F. (2005). Metodologi Pengajaran Bahasa Arab. Malang: Misykat.

Emzir. (2007). Metodologi Penelitian Pendidikan. Jakarta: Rajawali Pers.

Hidayat, D. R. (2005). Pendekatan CTL Sebagai Model Kontemporer Pembelajaran Bahasa (Makalah yang disajikan pada Seminar Internasional di Kenari Hotel, Makassar, 810 September 2005).

Nasution, S. \& Zulheddi. (2020). The Establishment of The Arabic Learning Environment in Islamic Higher Education Institution in North Sumatera. Arabiyat: Journal of Arabic Education and Arabic Studies, 7(1), 1-12. http://dx.doi.org/10.15408/ a.v7i1.13374. 
Sahrani. (2019). Ta'lim Maharatai al-Istima' wa al-Kalam al-Fa"al min Khilal alMasrahiyyah al-Ardiyyah (Bahs Tajribiy fi Tullab al-Mustawa al-Rabi' bi Jami'ah Pontianak al-Islamiyyah). Alsinatuna: Jurnal of Arabic Linguistics and Education, 4(2), 263-288. https://doi.org/10.28918/alsinatuna.v4i2.204

Sudijono, A. (2007). Pengantar Statistik Pendidikan. Jakarta: RajaGrafindo Persada.

Sugiyono. (2011). Metode Peneliian Kuantitatif, Kualitatif, dan R\&D. Bandung: Alfabeta.

Sukardi. (2003). Metodologi Penelitian Kompetensi dan Praktiknya. Yogyakarta: Bumi Aksara.

Tiro, M. A. (2003). Dasar-Dasar Statistik. Makassar: UNM.

Warsito, H. (1992). Pengantar Metodologi Penelitian. Jakarta: PT Gramedia Pustaka Utama. 